\title{
Mobile-Assisted Language Learning for EFL: A Conceptual Framework based on the Meta-UTAUT Model
}

\author{
Mohammad Rezaur Razzak ${ }^{1}$ and Suaad Jassem ${ }^{2}$ \\ ${ }^{1}$ Sultan Qaboos University, Muscat, Oman \\ ${ }^{2}$ Al-Zahra College for Women, Muscat, Oman \\ Im.razzak@squ.edu.om, ${ }^{2}$ suaad@zcw.edu.om
}

\begin{abstract}
The wide usage of smart mobile phones has drawn policymakers and educators towards the deployment of technology for mass education programs. Particularly in societies where English is not widely spoken, Mobile-Assisted Language Learning (MALL) is seen as an effective tool for educating citizens in learning English as a Foreign Language (EFL). However, despite the availability of broadband Internet and smartphones, the usage of MALL for EFL is not widely used by most non-native speakers. Therefore, it is imperative to determine the factors that drive the technology usage behavior of potential EFL learners. This study proposes a conceptual framework that presents factors that are potential drivers of behavioral intention and actual usage of MALL by EFL learners. The framework is based on the latest version of the Unified Theory of Acceptance and Use of Technology Model (known as meta-UTAUT). The framework theorizes that technology usage behavior is driven by performance expectancy, effort expectancy, social influence, and facilitating factors related to the technology. Furthermore, the relationships between the MALL usage behavior and its' drivers are potentially mediated by the attitude of the learners towards the technology. The outcome of this study is expected to pave the path for future researchers to undertake studies to test the framework to develop an empirically tested model.
\end{abstract}

Keywords: Mobile-Assisted Language Learning MALL, Technology usage behavior, MetaUTAUT, English as Foreign Language (EFL)

\section{Introduction}

The ubiquitous presence of smart mobile devices, such as mobile phones is viewed as a powerful tool through which mass learning and information dissemination can be implemented [1]. In this context, teaching widely spoken foreign languages such as English, through mobile applications is being deployed in many countries where English is not the native language [2]. The use of mobile systems for teaching English as a Foreign Language (EFL) is generally referred to as MALL (Mobile Assisted Language Learning) [3].

Against the backdrop of innovations in hyper-connected mobile applications that have created user-friendly and robust interfaces, numerous pedagogical practices and educational applications that facilitate collaborative learning are now being deployed around the world [1]. For countries where the English language is not the native language, such as in the GCC

Article history:

Received (July 11, 2021), Review Result (September 2, 2021), Accepted (November 4, 2021) 
countries; policymakers deem it necessary to make the use of the English language common among the populace [4], where MALL offers a powerful platform to implement such a goal.

In theory, the use of MALL offers various advantages such as access to experienced language teachers from any part of the world that can be connected to students in remote parts of any country [5]. Nevertheless, there is insufficient empirical evidence on whether the targeted users of MALL are comfortable with using mobile phone applications to learn a foreign language [6]. Without a finer-grained understanding of the drivers of perceptions of targeted MALL users regarding their behavioural intentions to use such technology, any efforts by policymakers and practitioners may be misdirected leading to failure in meeting intended goals [2][7].

The academic literature indicates that there is a rising scholarly interest in investigating the usefulness of MALL applications in EFL, yet there seems to be a dearth of sufficient understanding on what factors drive intentions of users of MALL [Appendix-A lists recent studies on MALL]. This study proposes a conceptual framework to examine the factors that are likely predictors of behavioural intention towards usage of MALL by EFL learners. In doing so, the meta-UTAUT Model proposed by Dwivedi et al. in 2019 [8], is used to develop a set of propositions positing relationships between the exogenous variables that are likely antecedents of Intention to Use and actual usage of MALL. The meta-UTAUT differs from the original UTAUT proposed by Venkatesh et al. in 2003 [9], as it discards all the moderators as being contextual, and adds the construct "Attitude to Use" as an intervening variable. The attitude was a construct in the original Technology Acceptance Model (TAM) proposed by Davis et al. in 1989 [10] and also in the TAM-2 model by Venkatesh and Davis (2000) but was later dropped in all versions of the UTAUT models [8].

Additionally, the meta-UTAUT model proposes a direct relationship between "facilitating conditions" and "usage behaviour", and also that "behavioural intention" partially mediates the relationship between "attitude to use" and "actual usage behavior". Despite the novelty presented in this model, so far there appears to be insufficient empirical research on the validity of the meta-UTAUT model, and hence the new model warrants further empirical validation as noted by Dwivedi et al. in 2020 [11] and Huseynov, Ozkan, and Yildrim in 2020 [12].

In addition to the above discourse, empirical evidence from previous social-psychology theories that enable prediction of peoples' behavior related to complex decisions, such as the Social Cognitive Theory-SCT [13], indicates that self-efficacy plays a role in how people behave when faced with new circumstances that demand substantial cognitive effort. Some empirical studies that used the earlier technology acceptance models such as TAM have tested self-efficacy as an exogenous variable and found it to be a significant moderator [14][15][16]. Furthermore, Chao et al. in 2019 [17] proposed a more contextualized definition by testing mobile self-efficacy as a moderator in the UTAUT model, to test its role in Mlearning, and found it to be significant. Nevertheless, the present meta-UTAUT model does not consider the self-efficacy of users. Therefore, based on empirical studies from other technology contexts, the current study proposes mobile self-efficacy as a potential moderator between behavioral intention to use MALL and its' antecedents.

This research examines the existing literature on Intention to Use and Actual Usage of learning technologies such as MALL by EFL learners and proposes a conceptual framework that identifies potential factors that drive intention of MALL users for effective learning of foreign languages such as English by non-native speakers. The proposed conceptual framework in this study will also posit that the relationships between "Behavioural Intention to use MALL" and its antecedents are moderated by the "Mobile Self-Efficacy" of the MALL 
users. This moderating variable is proposed with the support of the Social Cognitive Theory [13]. This study will also contribute to policymaking in countries that are trying to prioritize the learning of English by their citizens to build proficiency in communication with a more globalized world [4].

\section{Literature review}

The academic literature on behavioural intentions and actual usage regarding use of technology is quite rich and has been extensively studied since the proposition of the Technology Acceptance Model (TAM) by Davis in 1989 [18], which was a result of Davis's doctoral work completed in 1986 [19]. TAM is considered as a seminal work that combines the premise of some of the well-established behavioural theories such as Theory of Planned Behaviour (TPB) by Ajzen [20] and Theory of Reasoned Action (TRA) by Azjen \& Fishbein [21] and provides a robust lens into the understanding of user acceptance behaviour with regards to information and communication technology [22]. Theoretical models for the study of perceptions of technology users are not just limited to TAM, TPB, and TRA. The other established theories such as Decomposed Theory of Planned Behaviour [23], Motivational Model [24], Innovation Diffusion Theory [25], and Social Cognitive Theory [13] among many others have been widely used [19]. Furthermore, TAM went through several stages of evolution until the proposition of the Unified Theory of Acceptance and Use of Technology also known as UTAUT [9].

Before the proposition of the UTAUT, several researchers pointed out the fact that the models used in the past for studying technology acceptance address different research problems and are context-specific, meaning that important constructs that are unique to each model may be ignored in other situations [8]. This phenomenon attenuated the explanatory power of each of the parsimonious technology acceptance models [26]. Realizing this concern, Venkatesh and colleagues [9] developed the UTAUT by integrating eight different theories that include the different versions of TAM. The core premise of UTAUT is that intention to use a certain technology and actual use of the technology is driven by four factors: performance expectancy, effort expectancy, social influence, and facilitating condition, while these relationships are moderated by four other variables (i.e., age, gender, experience, and voluntariness) [27]. Following the proposition of the UTAUT, the model has been widely deployed in studies related to using of technology in multitudes of contexts, including the use of internet-based platforms such as websites, podcasts, blogs, vlogs, interactive whiteboards, video conferencing, MALL, etc. [28][29].

Although the UTAUT has proven to be quite useful in studying technology acceptance behaviour, particularly in the field of information technology, a comprehensive review of UTAUT by Dwivedi and colleagues [8] reveals several limitations of the model. First, very few empirical studies have explored the entire UTAUT model proposed by Venkatesh et al. in 2003 [9], opening up the question of whether the entire model is valid for all contexts. Second, the moderators such as "age" or "gender" used in the model appear to be contextual and may not be applicable in all situations. Third, the original UTAUT model excludes a vital construct "attitude towards the use of technology" that is likely to mediate the relationships between "intention to use technology" and its antecedents. Finally, in the original model, the path from "facilitating condition" to "usage behavior" has been omitted, and should be included according to Dwivedi et al. [8]. The aforesaid study examined 162 articles published in top-tier journals (i.e., publications in Scopus and Web of Science indexed journals) that used the original UTAUT model to study the acceptance of technology to make their case 
based on the abovepoints and developed a "meta-UTAUT Model" [Figure 1.0] as an improved version of the original model [29].

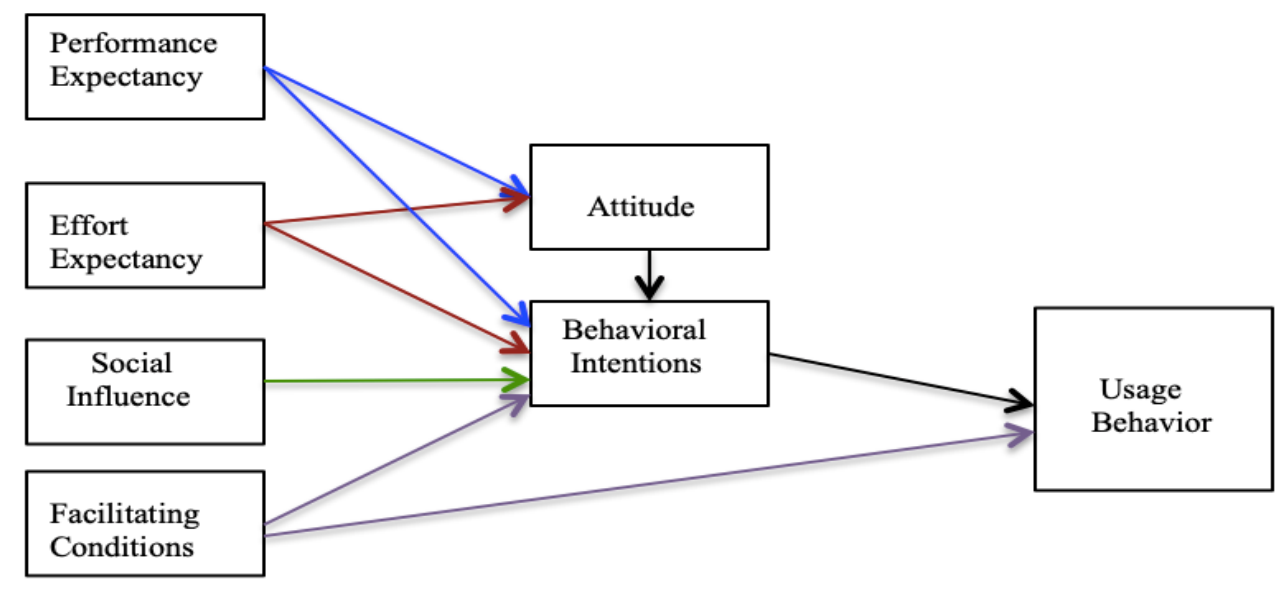

Source: Dwivedi et al. (2019)

Figure 1. Meta-UTAUT (Unified Theory of Acceptance \& Usage of Technology) model

A citation analysis of subsequent journal publications on the meta-UTAUT, reveals that so far (i.e., until June 2021) seventy-one (71) citations are listed on the Scopus database. The largest category (20 articles) was studies that selected variables that are similar to the constructs used in meta-UTAUT to support the hypotheses proposed in those studies. The second category was studied that cites meta-UTAUT in the literature review sections (19 articles). The third category (15 articles) was where the model was cited to explain the evolution of the technology acceptance models. The fourth category (10 articles) used the reference of meta-UTAUT to support arguments regarding their findings. The fifth category is studies that mention the model under limitations of their research. Finally, only three (3) articles empirically test the meta-UTAUT model with survey data, these are [28][29] and [12]. Of these three articles, the study by Hoi in 2019 [29] appears to be the only one that focuses on user acceptance behaviour for MALL.

The above discourse reveals that although the meta-UTAUT model appears to address the shortcomings of previous technology acceptance models, yet there seems to be a dearth of sufficient empirical studies that would enable theory testing for further validation of this model. Furthermore, although empirical research on perceptions of users regarding MALL for EFL does exist that have deployed other models such as TAM, UTAUT, and other sociopsychological theories such as TPB and TRA, yet there is insufficient understanding on how behavioural perceptions of MALL users would be impacted based on the predictors included in the meta-UTAUT model. Therefore, it seems that a significant gap in the body of knowledge exists and needs to be addressed. Based on the preceding discourse, the current study presents a set of propositions based on the meta-UTAUT model in the context of MALL for EFL, to posit relationships between factors that influence attitude, intentions, and actual usage of MALL applications.

The study by Hoi [29] using the meta-UTAUT model in the context of MALL usage in Vietnam, found that some of the relationships stipulated by Dwivedi et al. [8], regarding antecedents of behavioural intention, such as effort expectancy and attitude were found to be 
statistically non-significant. These results conflict with some of the prior empirical studies done with the original UTAUT model [11][30].

Based on guidelines from methodology scholars [31][32], inconsistencies in relationships between a given criterion variable and predictor variables may indicate that a theoretically justified moderator needs to be applied. In this case, based on the support from social cognitive theory [13], there is a possibility that mobile self-efficacy moderate the relationships between behavioural intention to use MALL and its drivers. Furthermore, mobile self-efficacy has been shown to influence behavioural intention in the case of Mlearning by Mahat et al. in 2012 [34] in the context of Malaysia. Therefore, based on the guidelines by MacKinnon [32], when there are inconsistencies between an outcome variable and its predictors, and an additional exogenous variable has been found to influence the outcome variable evidenced from prior studies, then the exogenous variable may be posited as a potential moderator. Hence, it may be deemed justified to test mobile self-efficacy as a moderator in the current framework. Such a result if found valid is expected to be a significant contribution to the understanding of how the meta-UTAUT model enables consistent prediction of relationships between behaviour of users of MALL and its' drivers.

The preceding discourse is presented to suggest that there is a possibility that mobile selfefficacy is a pertinent moderating variable in the meta-UTAUT model, and needs to be tested. This proposition is also in alignment with the premise of the social cognitive theory (SCT). Bandura [13] argues that SCT's core assertion is that beliefs about outcomes (e.g., performance expectancy or effort expectancy) may be insufficient to influence behaviour if individuals doubt their capabilities to successfully undertake such actions. Bandura further argues that self-efficacy, in addition to outcome expectations, must be considered. The author states that: "individuals can believe that a particular course of action will produce certain outcomes, but if individuals entertain serious doubts about whether they can perform the necessary activities such information does not influence their behaviour" (p.122).

In a study on acceptance and usage of MALL by higher education students by Botero et al. in 2019 [28], the authors assert that there are relatively few studies that report acceptance of mobile-assisted language learning, with even fewer studies in the context of developing countries where the majority of the citizens are non-native English speakers. Furthermore, the study by Hoi [29] mentioned earlier, seems to be among the few empirical studies so far that apply the meta-UTAUT to examine technology acceptance behaviour related to MALL [11]. The study investigates MALL usage behaviour among higher education students in Vietnam using data from 293 respondents. The results of the analysis in the study found that three of the relationships posited in the meta-UTAUT model are non-significant.

In terms of several studies that investigate MALL usage for EFL learners in the context of the Middle East, the few empirical studies available in the extant literature such as [4][7][34][35] indicate that majority of these studies have utilized theories such as Theory of Planned Behaviour, Theory of Reasoned Action or the original TAM model [4]. The recent study by Al-Qarni et al. in 2020 [4] focuses on learning Arabic through MALL by non-Arabic speakers. In terms of investigating MALL usage behavior for EFL learners, there appears to be a need for further research to develop a more robust model that enables the prediction of factors that drive perceptions of MALL users who are aiming to learn English as a foreign language. 


\subsection{Performance expectancy}

Performance expectancy is defined as the degree to which an individual believes that using the system will help them to attain enhanced job performance. This variable was constructed from previous constructs by Venkatesh et al. [9], which looked at: perceived usefulness from TAM and TAM2, extrinsic motivation from the motivation model, relative advantage from infusion diffusion theory, and outcome expectations from social cognitive theory. Venkatesh et al. [22] assert that the performance expectancy construct is expected to be the strongest predictor of intention and is consistently significant.

\subsection{Effort expectancy}

Effort expectancy is defined as the degree to which an individual perceives that the system to be used is easy to use [9]. This variable was developed from three previous constructs: perceived ease of use from TAM2, complexity from the model of PC utilization (MPCU), and ease of use from the infusion diffusion theory, by Venkatesh et al. [9]. At first glance, this construct appears to be the same as the other three constructs, but in reality, it is quite distinct [22].

\subsection{Social influence}

Social influence defines the degree to which an individual perceives that those people they consider as role models or whose opinions are important to them consider the system to be useful [9]. In previous models, social influence has been represented as a subjective norm based on TRA and TAM-2, as social factors through MPCU, and image through infusion diffusion theory. Although these variables have different labels, the underlying implication is that a person's behaviour is influenced by those they associate with and believe that such individuals tend to make the right choices [22].

\subsection{Facilitating condition}

Facilitating conditions are defined as the degree to which an individual believes that the organization they serve under, makes available to them the necessary infrastructural support to effectively use the system [9]. These variable captures conceptualization from three different constructs: perceived behavioral control based on the combined-TAM-TPB, facilitating conditions based on MPCU, and compatibility from the perspective of the infusion diffusion theory [22]. The construct reflects initiatives taken by the organization to remove any barriers in using the technology. Hence, this concept measures the perceptions of the users in terms of the support infrastructure available to enable seamless use of the technology.

\subsection{Attitude towards the use}

Attitude is an individual's positive or negative feelings about performing the target behavior [24]. The variable attitude towards using technology was developed from four previous constructs: attitude toward behavior based on TRA, TPB, and the Combined-TAMTPB, intrinsic motivation from motivation model, affect toward use from the MPCU and affect from the social cognitive theory [22]. The construct reflects the general feeling of the user associated with a given behavior (in this case technology use). It is evident that this construct taps into an individual's liking, enjoyment, and pleasure associated with the use of technology. 


\subsection{Behavioral intention}

Behavioural intention is defined as the measure of the strength of one's intention to perform a specific behaviour [21]. This refers to the motivational factors that influence a given behaviour where the stronger the intention to perform the behaviour, the more likely the behaviour will be performed. Correlational studies show that intentions are significantly associated with behaviour. For instance, in a meta-analysis by Armitage and Connor [36] of 185 studies that have used the TPB, the authors found that the sample-weighted average correlation between measures of intention and behaviour was significant. Based on the Theory of Planned Behaviour (TPB), the concept predicts an individual's intention to engage in behaviour at a specific time and place. The theory was intended to explain all behaviours over which people can exert self-control. The key component to this model is behavioural intent; behavioural intentions are influenced by the attitude about the likelihood that the behaviour will have the expected outcome and the subjective evaluation of the risks and benefits of that outcome [20].

\subsection{Usage behavior}

Usage Behaviour defines the actual application of the system by the user in their workplace and tasks. This construct is better measured through observations, although, in some studies, the perceptions of the users have also been used by recording their statements on the extent to which, they use the system at the workplace. However, several scholars including the proponents of TAM and UTAUT have cautioned researchers about measuring this variable without actual observations [37]. Most empirical studies using these models have omitted any hypotheses connecting to actual usage behaviour due to measurement issues [11].

\subsection{Self-efficacy}

Self-efficacy (SE) refers to an individual's belief that they can succeed given any task that they encounter [38]. SE can be general or task-specific, allowing individuals to have a range of SE beliefs about themselves at any one time. An individual's beliefs surrounding their levels of SE can have an impact on how they feel, think, and motivate themselves. This can lead to significant contrasts in behaviour between individuals with differing levels of SE. Those with a strong sense of SE believe in their capabilities deeply, seeing challenges as tasks to be mastered rather than threats to be avoided [39]. They also engross themselves in tasks and exert strong commitment. Any setbacks they encounter are easily recovered and learned from.

The above factors can all lead to enhanced personal well-being by reducing stress, resulting in the individual being less likely to experience anxiety related to technology usage. Others with a weak or low sense of SE have major doubts over their capabilities. This can lead to total avoidance of challenges as they see them as threatening situations. These individuals can spend a lot of time focusing on their previous failings and this can lead to setbacks being difficult to recover from. For this reason, these individuals can be more vulnerable to anxiety and stress [39].

\subsubsection{Mobile self-efficacy}

The previous section presented a discussion on general self-efficacy. The current study works with task-specific self-efficacy, which is, in this case, referred to as mobile selfefficacy [41]. General SE beliefs mirror the definition provided by Bandura [38], that: "the 
belief in one's capabilities to organize and execute the courses of action required to manage prospective situations" (p.84). This means that general SE is concerned with an individual's self-belief that they can do the desired work at any time that is not context-specific. While, task-specific SE beliefs (such as mobile self-efficacy), refer to an individual's self-belief that they can complete a specialized set of tasks, or in this case effectively use MALL applications for EFL. In Venkatesh and Bala's [41] TAM-3 model, the authors have included computer self-efficacy as one of the drivers of Perceived Ease Of Use (PEOU).

According to the Social Cognitive Theory (SCT), self-efficacy refers to people's assessments of their effectiveness or ability to perform a specific task well; it is related not to the skills of an individual but rather to how he or she perceives their ability to utilize these skills [13]. In this context of this study, self-efficacy is an individual's personal belief that he or she possesses the aptitude and skills to succeed when engaging in using MALL-related technology for learning English as a foreign language [41].

Although computer self-efficacy has been used in several empirical studies between 2008 till 2019, it appears that there are relatively fewer empirical studies that use mobile selfefficacy as a construct [43]. There seems to be a dearth of sufficient studies that have investigated the possible effects of mobile self-efficacy on various relationships between behavioral intentions to use and its antecedents showed in the meta-UTAUT model.

\section{Conceptual framework}

The subsequent sections delve into the process of development of a set of propositions that are based on the meta-UTAUT Model. The propositions lead to the development of a conceptual framework with the support of evidence from the literature and rational arguments.

\subsection{Relationship between performance expectancy and attitude}

Venkatesh et al. [9] defined performance expectancy as the degree to which users of technology-based systems believe that using the system will help them to attain their performance goals. Therefore, in the case of learning English as a foreign language through MALL, the learners would harbor expectancies that this mobile system would enable them to rapidly achieve fluency in the language. Although the definition of MALL varies from one study to another, yet the key features of MALL are consistent across all these studies, namely adaptability, accessibility, and flexibility of using the system at a time and place of convenience to transfer learning of any language [44]. The portability and mobility of using MALL through web-browsers and mobile applications that enable them to access interactive content supported by smart pedagogy create a certain level of performance expectancy among the users. Such performance expectancies regarding the system are likely to create a positive attitude towards the benefits of using MALL to learn English. Therefore, it may be posited that higher levels of performance expectancy of MALL users will lead to a more positive attitude towards MALL. Formally stated:

P-1: Performance expectancy has a positive relationship with Attitude towards the use of MALL.

\subsection{Relationship between performance expectancy and behavioral intention}

The original postulation of TAM was that whenever users of new technology view that the usefulness of the system is high, they tend to translate such perceptions towards intention to 
use the system [10][23]. The positive relationship between expected performance expectancy and behavioural intention is also in line with the Theory of Planned Behaviour (TPB), which asserts that when individuals can see clear usefulness of some action, they solidify their intentions to indulge in behaviour that leads to the benefits derived from such action [20].

When learners of the English language as a foreign language use the mobile application that enables learners of a language that is quite different from their native language, they are likely to continue to be engaged in using the system. Furthermore, Hoi et al. [29] in their study in the context of the use of MALL in Vietnam also found a significant relationship between performance expectancy and intention to use. Therefore, it is posited that:

P-2: Performance expectancy has a positive relationship with Behavioural Intention towards the use of MALL.

\subsection{Relationship between effort expectancy and attitude}

Effort expectancy has been defined as the extent to which the users of a technological system perceive that the system is relatively easy to use in achieving their objectives [9]. In the case of this study, effort expectancy will reflect the degree to which users of MALL for EFL view that the system is quite easy to use. One of the premises of the social cognitive theory [13], is that when human beings consider engaging in any action that they perceive as complex, they will automatically develop an attitude of avoidance. This means that if the level of effort to use a system such as MALL appears to be difficult, then the users will be discouraged to use it. Therefore, it may be inferred that the opposite will be true when the perception of users shows that they feel that the system is easy to use, and such feelings will lead to a positive attitude towards the system. Hence, it may hypothesize that:

P-3: Effort expectancy has a positive relationship with Attitude towards the use of MALL.

\subsection{Relationship between effort expectancy and behavioral intention}

Behavioural intention to commit to any action is influenced by whether the individual views the action to be free of complexity and difficulty in execution. This causal relationship is derived from the theory of reasoned action [21]. In the study of the use of MALL in Vietnam, Hoi et al. [29] demonstrated that the perceptions of MALL users towards ease or difficulty of using such system for learning languages had an impact on their intentions to use the system. The same situation is likely to be manifested in the context of countries where the English language is completely different from the native language (e.g., Arabic or Chinese). Therefore, the smart pedagogical tools that are deployed in delivering malls such as interactive games, grammar corrections, vocabulary enhancement tools, and performance assessment tests, need to be perceived as easy to use by the learners. Thus, when the learners feel that the mobile applications are easy to use, they are likely to manifest higher degrees of intention to use the system. Formally stated:

P-4: Effort expectancy has a positive relationship with Behavioural Intention towards the use of MALL.

\subsection{Relationship between social influence and behavioral intention}

Venkatesh et al. [9] have defined social influence as the degree to which an individual user of a technology-based system is influenced by others who are using or avoiding the use of the system. Such influencers are typically individuals that are seen by users as people whose 
judgments and decisions are superior to theirs. The influence of others is a major factor in the use of computers and information systems. According to the Model of PC Utilization by Thompson et al. [45], social influence has a strong coefficient (i.e., standardized $\beta$-value) in its impact on intention to use PCs. Similarly, in the Model of Acceptance with Peer Support (MAPS) by Sykes et al. [46], the authors indicate that the social influence of peers has a significant influence on users of information systems. Therefore, in the case of MALL for EFL, it is expected that social influence will have an impact on behavioural intention to use MALL. Hence, it is posited that:

P-5: Social Influence has a positive relationship with Behavioural Intention towards the use of MALL.

\subsection{Relationship between facilitating condition and behavioral intention}

Facilitating conditions may be defined as the degree to which individual users of a system believe that the organization that is providing the system is also providing the right technical infrastructure to support seamless use of the system [9]. In many studies, facilitating conditions have been reflected through perceived organizational support (POS). However, Dwivedi et al. [8] clearly distinguish between facilitating conditions and POS. They state that POS is a much broader umbrella construct, whereas, facilitating condition addresses the technical infrastructure primarily. The UTAUT2 model by Venkatesh and colleagues [22], indicates that facilitating conditions influences intentions to use a system. Therefore, it may be posited that perceptions of the facilitating conditions will influence the users' intention to use MALL. Formally stated:

P-6: Facilitating condition has a positive relationship with Behavioural Intention towards the use of MALL.

\subsection{Relationship between facilitating condition and usage behavior}

This assertion made in the preceding section about the influence of facilitating conditions on behavioural intention may also be extrapolated to the relationship with actual usage. The same rationale may be used in the relationship between facilitating conditions and actual usage. For instance, the content that is used in MALL applications is large files that are created by the providers of MALL applications. The interactive modules, the gamification applications, the performance evaluation systems, etc., require substantial bandwidth for smooth access by users. Therefore, for effective usage of MALL, the learners need to be able to access the system through high-speed broadband Internet connections from any location, without being confined to a designated location. Without such infrastructure is available, the point of having mobile applications will be vitiated. Therefore, if learners can access the system seamlessly from anywhere and at any time, then they will be using the system more frequently. The opposite would be true if the facilitating conditions are perceived to be poor. Therefore, it is hypothesized that:

P-7: Facilitating condition has a positive relationship with Usage Behaviour of MALL.

\subsection{Relationship between attitude and behavioral intention}

Dwivedi et al. [8] brought back the construct, Attitude to the meta-UTAUT model which was present in the TAM models; however, it was dropped by Venkatesh and colleagues in their subsequent models of UTAUT. Attitude has been defined as an individual user's positive 
or negative feelings about performing a targeted behaviour [23]. In the case of MALL for EFL, this variable would reflect the emotions of the learner in terms of the system are being able to derive the benefit of learning English. Dwivedi et al. [8] argue that without bringing attitude into the model, the picture is incomplete. The authors draw from the arguments made by Ajzen and Fishbein [21] about the influence of emotions on the intentions of people towards certain behaviour. Therefore, in this case, if learners have a strong and positive emotion regarding the benefits of MALL, they are likely to develop strong intentions to perform such behaviour. Therefore:

P-8: Attitude has a positive relationship with Behavioural Intentions towards MALL.

\subsection{Relationship between behavioral intention and usage behavior}

The relationship between behavioural intention and usage behaviour has been drawn from multiple social psychology theories such as Theory of Reasoned Action-TRA and Theory of Planned Behaviour-TPB, etc. For instance, TRA posits that an individual's actual behaviour is driven by the individual's intention, which in turn is a function of various factors such as attitude towards the behaviour and subjective norms [21]. In the development of TAM, Davis et al. [10] utilized the basic premise of TRA to propose that usage of information systems was driven by perceived ease of use and perceived usefulness, and the relationships are accounted for by the behavioural intention of the users. Therefore, it may be posited that behavioural intention drives user behaviour. Formally stated:

P-9: Behavioural Intentions has a positive relationship with Usage Behaviour towards MALL.

\subsection{Mediating effect of attitude between performance expectancy, effort expectancy, and behavioral intention}

A person's intentions to commit to certain behaviour may be shaped by the extent to which they feel inclined towards such behaviour (i.e., their attitude towards it) [47]. Attitude on the other hand is likely to be shaped by factors that influence their emotions, such as their perceived expectancies in terms of how easy the system is to use (i.e., views about the complexity of the system) and its performance in achieving desired performance objectives (i.e., the usefulness of the system) [8]. While, the direct relationships between performance expectancy and effort expectancy with behavioural intentions have been posited to be significant, yet there is a strong likelihood that, part of the relationship between the above variables is accounted for by attitude towards the use of the technology. Therefore, based on the inferences drawn from the empirical studies by Rana et al. [47] and also by Dwivedi et al. [8], it may be posited that attitude partially mediates the relationship between performance expectancy and effort expectancy, on behavioural intention to use MALL. Therefore, the following two mediation effects are posited:

P-10a: Attitude mediates the relationship between Performance Expectancy and Behavioural Intentions towards usage of MALL.

P-10b: Attitude mediates the relationship between Effort Expectancy and Behavioural Intentions towards usage of MALL. 


\subsection{Mediating effect of behavioral intention between performance expectancy, effort expectancy, social influence, facilitating condition, attitude, and usage behavior}

According to the meta-UTAUT model, the relationships between factors that drive intentions to behave (e.g., intention to use MALL for learning English), are assumed to be driven by performance expectancy, effort expectancy, social influence, and facilitating condition. These relationships have been established by Venkatesh et al. [9] based on the UTAUT model. The addition to these relationships posited by Dwivedi et al. [9] is that attitude also drives intentions along with the above four variables. In terms of relationships of all the above five factors with behavioural usage, four of these factors (i.e., performance expectancy, effort expectancy, social influence, and attitude), the linkages are posited to be fully mediated by behavioural intention to use MALL. Only in the case of facilitating conditions the mediation effect is assumed to be partial. Therefore, the following are proposed:

P-11a: Behavioural Intention mediates the relationship between Performance Expectancy and Usage Behaviour towards MALL.

P-11b: Behavioural Intention mediates the relationship between Effort Expectancy and Usage Behaviour towards MALL.

P-11c: Behavioural Intention mediates the relationship between Social Influence and Usage Behaviour towards MALL.

P-11d: Behavioural Intention mediates the relationship between Facilitating Condition and Usage Behaviour towards MALL.

P-11e: Behavioural Intention mediates the relationship between Attitude and Usage Behaviour towards MALL.

\subsection{Moderating effect of mobile self-efficacy}

Several empirical studies that have deployed the original UTAUT model in different contexts other than computer usage and information systems have shown some degree of inconsistencies in the relationships between behavioural intention and its' four predictors (performance expectancy, effort expectancy, social influence, and facilitating condition) (Botero et al., 2019). For instance, Hoi et al. [29] show that the relationships between effort expectancy and behavioural intention were statistically non-significant. This result conflicts with several studies done on computer and information usage [11]. Based on guidance from methodology scholars [31][32], when inconsistency is observed in relationships between an outcome variable and its predictors, there is a possibility that the relationships will be strengthened by the application of a theoretically justified moderator.

In the study by Mahat et al. [33], the authors assessed the mobile efficacy of students in Malaysia with regards to readiness, personal innovativeness, and behavioural intention towards usage of mobile learning in higher education. In the aforesaid study, mobile selfefficacy was defined as the students' self-belief that they could successfully apply learning applications in a blended learning environment. The study showed that mobile self-efficacy had a positive and significant influence on behavioural intention to use mobile learning. Based on the guidelines [32], when there are inconsistencies between an outcome variable and its predictors, and an additional exogenous variable have been found to influence the outcome variable, and then the exogenous variable may be tested as a potential moderator. 
Furthermore, Reychav et al. [48] conducted a study on the role of mobile self-efficacy of patients being monitored through a telemedicine system, with the use of self-monitoring mobile devices. The study found that the relationship between behavioural intention to use the system for self-monitoring by patients and its antecedents was moderated by the self-efficacy of the users. Therefore, based on the preceding discourse, it may be posited that mobile selfefficacy of the MALL users moderates the relationships between behavioural intention to use MALL and its predictors. Formally stated:

P-12a: Mobile Self-Efficacy moderates the relationship between performance expectancy and behavioural intention.

P-12b: Mobile Self-Efficacy moderates the relationship between effort expectancy and behavioural intention.

P-12c: Mobile Self-Efficacy moderates the relationship between social influence and behavioural intention.

P-12d: Mobile Self-Efficacy moderates the relationship between facilitating condition and behavioural intention.

P-12e: Mobile Self-Efficacy moderates the relationship between attitude and behavioral intention

Based on the propositions developed in the preceding sections, the following conceptual framework emerges [Figure 2].

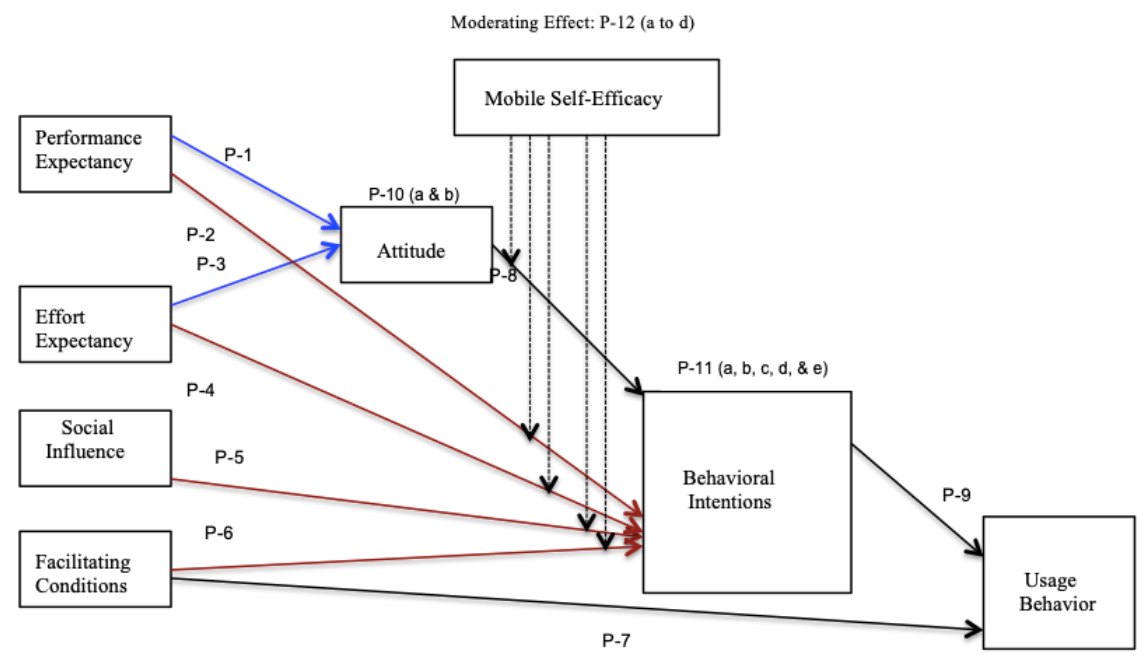

Figure 2. Conceptual framework of the current study

\section{Discussions and future research directions}

The primary objective of this study was to propose a conceptual framework that attempts to provide a holistic picture of the potential drivers of behavioural intentions and actual usage behaviour with regards to the acceptance of new technology such as mobile-assisted language learning. By examining the extant literature on the evolution of technology acceptance models, this study led to the development of a set of propositions by deploying a theoretical framework that was developed fairly recently, known as the meta-UTAUT Model. This 
model took into consideration the various criticisms in the literature about the previous models such as TAM, UTAUT, and their subsequent versions of technology acceptance behavioural models, and tried to propose a more robust framework on technology acceptance behaviour.

From the standpoint of contribution to the academic literature, the current framework not only proposes a potential model that may be able to identify significant antecedents of behavioural intentions to use and actual use of technology but also brings to limelight the potential moderating effect of mobile self-efficacy. The construct self-efficacy has been considered in some of the prior models based on Albert Bandura's seminal work on social cognitive theory. However, in subsequent frameworks, self-efficacy was omitted. The omission of such an important construct poses the likelihood of an incomplete picture of user behaviour when it comes to the use of new and complex technologies. Hence, by reintroducing self-efficacy into the picture, there is a possibility that the framework will have greater explanatory power.

In terms of signpost for future researchers, the first possibility is to empirically test the validity of this conceptual framework. One possibility is to undertake a survey of sufficient potential users of MALL and determine if the relationships posited in the framework are significant. To enhance the generalizability of such a study, the data needs to be collected from multiple geographic regions of the globe where English is not a native language. However, to develop a more robust model from this framework, a better option would be to conduct a randomized control experiment where the performance of student groups may be compared between those that were exposed to MALL and those that sued conventional methods to learn English. Such experimental studies would provide deeper insights into how technology usage behaviour is influenced by the different variables proposed in the framework.

\section{Conclusion}

Technologies such as MALL are modern-day learning tools that may be extremely useful in a globalized world. Many nations have been lagging in terms of fully benefiting from the positive aspects of a globalized world due to their citizens not being conversant in international languages such as English. Policymakers in countries where English is not commonly spoken by their general populace are adopting various programs and projects to enable their citizens to rapidly navigate the learning curve of knowledge in terms of global languages so that they can develop their economies through a more well-trained, skilled, and globalized workforce. Particularly for learning English as a Foreign Language, education planners are embracing new technologies that can achieve socio-economic development goals by accelerating the pace of learning such important languages. Therefore, the framework presented in the current study may pave the path for future empirical research to develop models based on data collected from different non-English speaking countries to identify the strongest driving factors of MALL acceptance. Such initiatives may be instrumental in creating a global community that is more conversant with international languages such as English. Such goals are not only tied to national goals but are also likely to create a world where people understand each other without barriers. 


\section{References}

[1] R. Shadiev, T. Liu, and W. Hwang, "Review of research on mobile-assisted language learning in familiar, authentic environments," British Journal of Educational Technology, vol.51, no.3, pp.709-720, (2020)

[2] K. O. Dagdeler, M. Y. Konca, and H. Demiro, "The effect of mobile-assisted language learning (MALL) on EFL learners' collection learning (online)," Journal of Language and Linguistic Studies, vol.16, no.1, pp.489$509,(\mathbf{2 0 2 0})$

[3] E. Darsih and N. A. Asikin, "Mobile assisted language learning: EFL learners' perceptions toward the use of mobile applications in learning English," Journal of English Education, vol.8, no.2, pp. 19-25, (2020)

[4] A. Al-Qarni, A. Brown, D. Pullen, and J. Masters, "Mobile assisted language learning in learning Arabic as a second language in Saudi Arabia," Saudi Journal of Humanities and Social Sciences, pp.108-115, (2020)

[5] K. E. M. Elshahawy, "Practicing English through digital devices: Practices and perceptions of the EFL undergraduate students majoring in English language," International Journal of Language and Literary Studies, vol.2, no.1, pp. 21-37, (2020)

[6] B. Zou, C. Yan, and Y. Li, "Students' perspectives on using online sources and apps for EFL learning in the mobile-assisted language learning context," Language Learning and Literacy, Shandong Publications, China, (2020)

[7] M. S. Keezhatta and A. Omar, "Enhancing reading skills for Saudi secondary school students through mobile assisted language learning (MALL): An experimental study," International Journal of English Linguistics, vol.9, no.1, pp.63-74, (2019)

[8] Y. K. Dwivedi, N. P. Rana, A. Jeyaraj, M. Clement, and M. D. Williams, "Re-examining the unified theory of acceptance and use of technology (UTAUT): towards a revised theoretical model," Information Systems Frontier, vol.21, pp.719-734, (2019)

[9] V. Venkatesh, M. G. Morris, G. B. Davis, and F. D. Davis, "User acceptance of information technology: Toward a unified view,” MIS Quarterly, vol.27, no.3, pp.425-478, (2003)

[10] F. D. Davis, R. P. Bagozzi, and P.R. Warshaw, "User acceptance of computer technology: A comparison of two theoretical models," Management Science, vol.35, no.8, pp.982-1003

[11] Y. K. Dwivedi, N. P. Rana, K. Tamilmani, and R. Raman, "A meta-analysis based modified unified theory of acceptance and use of technology (meta-UTAUT): a review of emerging literature," Current Opinion in Psychology, vol.36, pp.13-18, (2020)

[12] F. Huseynov, F. Ozkan, and S. Yildrim, "Online consumer typologies and their shopping behaviors in B2C ecommerce platforms," Sage Open Publications, California, vol.9, pp.9-18, (2019)

[13] A. Bandura, "Social foundations of thought and action: A social cognitive theory," Prentice Hall, Englewood Cliffs, USA

[14] M. S. Abbasi, A. Tarhini, M. Hassouna, and F. Shah, "Social, organizational, demography and individual's technology acceptance behavior: A Conceptual Model," European Scientific Journal, vol.11, no.9, pp.18571882, (2015)

[15] H. Sun and P. Zang, "The role of moderating factors in user technology acceptance," International Journal of Human-Computer Studies, vol.64, no.2, pp.53-78, (2006)

[16] D. Tao, F. Shao, and H. Wang, "Integrating usability and social cognitive theories with the technology acceptance model to understand young users' acceptance of health information portal," Health Informatics Journal, vol.55, no.2, pp.13-28, (2019)

[17] C. M. Chao, "Factors determining the behavioral intention to use mobile learning: An application and extension of the UTAUT Model," Frontier Psychology, vol.11, no.2, pp.157-178, (2019)

[18] F. D. Davis, "Perceived usefulness, perceived ease of use, and user acceptance of information technology," MIS Quarterly, vol. 13, no. 3, pp. 319-339 
[19] A. Ray, A., P. K. Bala, and A. A. Dasgupta, "Psychological analytics-based technology adoption model for Effective Educational Marketing," In: Rana N. et al. (eds) Digital and Social Media Marketing. Advances in Theory and Practice of Emerging Markets. Springer, Cham., (2020)

[20] ] I. Ajzen, "The theory of planned behavior. Organizational behavior and human decision processes," vol.50, no.2, pp.179-211

[21] I. Ajzen and M. M. Fishbein, "Understanding attitudes and predicting social behavior," Eaglewoods Cliffs: Prenctice-Hall, USA

[22] V. Venkatesh, J. Y. Thong, and X. Xu, "Consumer acceptance and use of information technology: Extending the unified theory of acceptance and use of technology," MIS Quarterly, vol.36, no.1, pp.157-178, (2012)

[23] S. Taylor and P. A. Todd, "Understanding information technology usage: A test competing models," Information Systems Research, vol.6, no.4, pp.144-176

[24] F. D. Davis, R. P. Bagozzi, and S. R. Warshaw, "Extrinsic and intrinsic motivation to use computers in the workplace," Journal of Applied Social Psychology, vol.22, no.14, pp.1111-1132

[25] E. M. Rogers, "Diffusion of innovations," Fourth Edition, The New York Free Press

[26] A. Granic and N. Marangunic, "Technology acceptance model in an educational context: A systematic literature review," British Journal of Educational Technology, vol.50, no.5, pp.2572-2593, (2019)

[27] K. Al-Saedi, M. Al-Emran, T. Ramayah, and E. Abusham, "Developing a general extended UTAUT model for M-payment adoption," Technology in Society, vol.62, pp.136-152, (2020)

[28] G. G. Botero, F. Questier, S. Cincinnato, T. He, and C. Zhu, "Acceptance and usage of mobile-assisted language learning by higher education students," Journal of Computing in Higher Education, vol.30, no.3, pp.426-445, (2019)

[29] V. N. Hoi, “Understanding higher education learners' acceptance and use of mobile devices for language learning: A Rasch-based path modeling approach,” Computer Education, vol.146, no.1, pp.1-15, (2019)

[30] A. Hossain, R. Quaresma, and H. Rahman, "Investigating factors influencing the physicians' adoption of electronic health record (HER) in the healthcare system of Bangladesh: An empirical study," International Journal of Information Management, vol.44, no.1, pp.76-87, (2019)

[31] A. F. Hayes, "Partial, conditional, and moderated mediation: Quantification, inference, and interpretation," Communication Monographs, vol.85, no.1, pp.4-40, (2018)

[32] D. P. MacKinnon, "Integrating mediators and moderators in research design," Research on Social Work Practice. vol.21, no.6, pp.675-681, (2011)

[33] J. Mahat, A. F. M. Ayub, and S. L. Wong, “An assessment of students' mobile self-efficacy, readiness and personal Innovativeness towards Mobile Learning in Higher Education in Malaysia," Procedia-Social and Behavioral Sciences, vol.64, pp.284-290, (2012)

[34] H. S. Mahdi, "The use of keyword video captioning on vocabulary learning through mobile-assisted language learning," International Journal of English Linguistics, vol.7, no.4, pp.1-7, (2017)

[35] A. A. M. H. Al-Ahdal and M. Shariq, "MALL: Resorting to mobiles in the EFL classroom," The Journal of Social Sciences Research, vol.1, pp.90-96, (2019)

[36] C. J. Armritage and M. Conner, "Efficacy of the theory of planned behavior: A meta-analytic review," British Journal of Social Psychology, vol.40, no.4, pp.471-499, (2010)

[37] M. M. Rahman, M. F. Lesch, W. J. Horrey, and L. Strawderman, "Assessing the utility of TAM, TPB, and UTAUT for advanced driver assistance systems,” Accident Analysis \& Prevention, vol.108, no.1, pp.361-373, (2017)

[38] A. Bandura, "Self-efficacy: Toward a unifying theory of behavioral change," Psychological Review, vol.84, no.1, pp.191-215

[39] A. Bandura, "Social cognitive theory of mass communication," In J. Bryant \& D. Zillmann (Eds.), LEA's communication series. Media effects: Advances in theory and research, Lawrence Erlbaum Associates, Inc., USA, pp. 61-90 
[40] S. A. Nikou and A. A. Economides, "Mobile-based assessment: Investigating the factors that influence behavioral intention to use," Computers and Education, vol.109, pp.56-73, (2017)

[41] V. Venkatesh and H. Bala, "Technology acceptance model 3 and a research agenda on interventions," Decision Sciences, vol.39, no.2, pp.273-315, (2008)

[42] A. B. Ozturk, A. Bibihan, K. Nusair, and F. Okumus, "What keeps the mobile hotel booking users loyal? Investigating the roles of self-efficacy, compatibility, perceived ease of use, and perceived convenience," International Journal of Information Management, vol.36, no.6, pp.40-55, (2016)

[43] I. Ali and N. F. Warraich "The relationship between mobile self-efficacy and mobile-based personal information management practices: A systematic review," Library of Hi-Technology, vol.39, no.1, pp.126$143,(\mathbf{2 0 2 0})$

[44] S. Loewen, D. Crowther, D. R. Isabell, K. M. Kim, Z. F. Maloney, and H. Rawal, "Mobile-assisted language learning: A Duolingo case study," ReCALL, vol.1, pp.1-19, (2019)

[45] R. L. Thompson, C. A. Higgins, and J. M. Howell, "Personal computing: Toward a conceptual model of utilization,” MIS Quarterly, vol.15, no.1, pp.124-143

[46] T. A. Sykes, V. Venkatesh, and S. Gosain, "Moodle of acceptance with peer support: A social network perspective to understand employees' system use," MIS Quarterly, vol.33, no.2, pp.371-393, (2009)

[47] N. P. Rana, Y. K. Dwivedi, M. D. Williams, and V. Weerakkody, "Adoption of online grievance redressal system in India: Toward developing a unified view," Computers in Human Behavior, vol.59, pp.265-282, (2016)

[48] ] I. Reychav, R. Beeri, A. Balapour, D. R. Raban, R. Sabherwal, and J. Azuri, "How reliable are selfassessments using mobile technology in healthcare? The effects of technology identity and self-efficacy," Computers in Human Behavior, vol.91, no.2, pp.52-61, (2019) 


\section{Appendix-A}

Table Depicting Peer-Reviewed Publications on MALL from 2019-2021

\begin{tabular}{|c|c|c|}
\hline No. & $\begin{array}{c}\text { Title, Double Blind Peer Reviewed Journal/Peer-Reviewed } \\
\text { Book-Chapter, Year }\end{array}$ & Authors \\
\hline 1 & $\begin{array}{l}\text { Mobile-assisted and gamification based language } \\
\text { learning: A systematic literature review, PeerJ } \\
\text { Computer Science, } 2021\end{array}$ & $\begin{array}{l}\text { Ishaq, Mat Zin, Rosdi, } \\
\text { Jehangir, Ishaq, \& Abid }\end{array}$ \\
\hline 2 & $\begin{array}{l}\text { The Effectiveness of Mobile-Assisted Language } \\
\text { Learning (MALL): A Review of the Extant } \\
\text { Literature, Book Chapter, } 2020\end{array}$ & $\begin{array}{l}\text { Kamasak, Rifat, Ozbilgin, } \\
\text { Mustafa \& Atay, Derin \& Kar, } \\
\text { Altar }\end{array}$ \\
\hline 3 & $\begin{array}{l}\text { MALL: Resorting to Mobiles in the EFL Classroom, } \\
\text { The Journal of Social Sciences Research, } 2019\end{array}$ & Al-Ahdal \& Shariq \\
\hline 4 & $\begin{array}{l}\text { Mobile Assisted Language Learning in Learning } \\
\text { Arabic as a Second Language in Saudi Arabia, Saudi } \\
\text { Journal of Humanities and Social Sciences, } 2020\end{array}$ & $\begin{array}{l}\text { Al-Qarni, Brown, Pullen, \& } \\
\text { Masters }\end{array}$ \\
\hline 5 & $\begin{array}{c}\text { The relationship between mobile self-efficacy and } \\
\text { mobile-based personal information management } \\
\text { practices: A systematic review, Library of } \mathrm{Hi} \\
\text { Technology, } 2020\end{array}$ & Ali \& Warraich \\
\hline 6 & $\begin{array}{c}\text { Acceptance and usage of mobile assisted language learning } \\
\text { by higher education students. Journal of Computing in } \\
\text { Higher Education, } 2019\end{array}$ & Botero \\
\hline 7 & $\begin{array}{l}\text { Factors Determining the Behavioral Intention to Use } \\
\text { Mobile Learning: An Application and Extension of the } \\
\text { UTAUT Model. Frontier Psychology, } 2019\end{array}$ & Chao \\
\hline 8 & $\begin{array}{l}\text { The effect of Mobile-Assisted Language Learning (MALL) } \\
\text { on EFL Learners' collection learning (online). Journal of } \\
\text { Language and Linguistic Studies, 2020 }\end{array}$ & Dagdalier, Knoca \& Demiro \\
\hline 9 & $\begin{array}{l}\text { Mobile Assisted Language Learning: EFL learners } \\
\text { Perceptions Toward the Use of Mobile Applications in } \\
\text { Learning English. Journal of English Education, } 2020\end{array}$ & Darsih \& Asikin \\
\hline 10 & $\begin{array}{l}\text { Understanding higher education learners' acceptance and } \\
\text { use of mobile devices for language learning: a Rasch-based } \\
\text { path modeling approach. Computer Education, } 2019\end{array}$ & Hoi \\
\hline 11 & $\begin{array}{c}\text { Enhancing Reading Skills for Saudi Secondary School } \\
\text { Students through Mobile Assisted Language Learning } \\
\text { (MALL): An Experimental Study. International Journal of } \\
\text { English Linguistics, 2019 }\end{array}$ & Kheezhata \& Omar \\
\hline 12 & $\begin{array}{l}\text { Mobile-assisted language learning: A Duolingo case study. } \\
\operatorname{ReCALL}, 2019\end{array}$ & $\begin{array}{c}\text { Lowen Crowther, Isbell, Kim, } \\
\text { Maloney \& Rawal }\end{array}$ \\
\hline 13 & $\begin{array}{c}\text { Review of research on mobile-assisted language learning in } \\
\text { familiar, authentic environments. British Journal of } \\
\text { Educational Technology, 2020 }\end{array}$ & Shadiev, Liu \& Hwang \\
\hline
\end{tabular}

